\title{
Is There any Chance for a Biologically-Oriented History of Psychiatry?
}

\author{
Krystyna Bielecka \\ University of Warsaw, Poland \\ kikab.gazeta.pl@gmail.com
}

Received 11 January 2019; accepted 25 April 2019; published 11 November 2019

\begin{abstract}
Historia polskiego szaleństwa (History of Polish Madness) by Mira Marcinów is the first book on the history of melancholy in Poland. Nowadays we use a term ,depression” instead of ,melancholy” so Marcinów's topic of study somehow corresponds to the concept of depression in modern psychiatry. In the first volume Stońce wśród czarnego nieba: Studium melancholii (The Study of Melancholy: The Sun with the Black Sky), Marcinów presents an original view on the history of the concept of Polish melancholy of the $19^{\text {th }}$ century. It is both a conceptual and fascinating historic work, a large part of which contains a collection of personal case studies, unknown previously to historians of psychiatry, found by Marcinów in diaries or other forgotten notes or records.

In my paper, I want to analyze her claims about the relation between medicine and psychology in Poland of the $19^{\text {th }}$ century that became a leitmotif of the book. Marcinów emphasizes that in the very beginning of psychiatry, all biological and psychological factors underlying psychopathologies (especially, melancholy) were understood as different and strictly separated. It contradicts the fact that psychiatric descriptions and explanations, as one can notice in the records cited, remind us of a mixed-bag of psychological and biological descriptions and explanations rather than a clear-cut distinction between them. My claim is that some of hidden philosophical assumptions that Marcinów slightly gestures toward in her book are responsible for the fact that such division between the mental and the somatic is so common in psychiatric explanations even nowadays (it is worth noticing that the situation in neuroscience is much different). I will then make explicit some of her philosophical assumptions (section 1). Furthermore, I will argue against Marcinów's assumption that psychology should be considered autonomously from medicine. I will claim that a mixed view on psychopathologies fits very well the historical facts and is much more fruitful. I will then present a draft of an alternative philosophical framework that
\end{abstract}


could rejoin two apparently different perspectives - psychological and medical — in order to explain further why some disordered mental states could have meaning (section 2) This alternative framework, in my opinion, would be useful in a more nuanced understanding of how the notion of melancholy emerged and eventually dissolved. In the last section, I will summarize the main points of the paper.

Keywords: history of psychiatry; melancholy; biology; medicine; psychology.

\section{Are There Really Two Paradigms?}

A methodological perspective that Marcinów takes in her book is a comparative analysis of some documented examples and observations. Her idea is to zoom in on phenomena in order to show separated medical and psychological descriptions or explanations of them:

For the purpose of this book, in which I examine some interesting issues in the very beginning of Polish psychopathology, I will use a comparative analysis between psychological account of mental disorders and accounts used in other sciences, especially medicine. I motivate my appealing to such analysis by the fact that psychological characteristic of madness was in opposition to somatic (Micale and Porter, 1994). (Marcinów, 2017, p. 38)

The main part of Marcinów's methodological concern is a so-called intellectual history (Foucault, 1970), which is a history of ideas of a certain society (Walicki, 2000). This is her basic methodological justification for analyzing peculiar cases and their descriptions to tease out the concept of melancholy that was being developed in Poland. I find concentrating on descriptions of personal stories well-motivated insomuch as interpretations of personal stories can tell us more about how the concept of melancholy was developing and demonstrate the disproportion between medical and psychological paradigms. Marcinów notices very cautious or underspecified psychological descriptions in the beginning of psychiatry of a disease of "melancholy", nowadays called depression:

Paying special attention mostly to these descriptions in mental disorders that are in opposition to a strict biological picture is to show a final indescribability of psychology in context of mental disorders. It does not mean that some interesting somatic explanations of mental disorders will be omitted, it means only that I will show in details some psychological interpretations but at the same time having in mind a variety of biological descriptions compared to some psychologizing ones. (Marcinów, 2016, p. 69-70)

\subsection{Philosophical Assumptions}

There are some characteristic philosophical assumptions hidden in stories of melancholics in the book that incited prejudice against thinking of melancholy in psychological terms in contradistinction and opposition to more biological explanations. A division between medical and psychological paradigms still exists - in some form nowadays and there is still a disagreement between (especially biologically-oriented) psychiatrists and clinical psychologists. It appears that mental health professionals firmly distinguish biological 
from psychological factors, contrary to what they think they actually believe (Ahn, Proctor, \& Flanagan, 2010). To some point, the existence of such division is understandable, because both fields are still in progress and of course nothing seems obvious concerning mental diseases. I do not want to disagree with that point. What I want to concentrate on is firstly a common distorted view of what, especially, biological explanations relate to and, secondly, what kind of philosophical assumptions underlie such view. Moreover, I will try to show how such assumptions influence the way the relation between somatic (medical, biological) and psychological (or broader, humanistic) explanations is seen as well as the way how patients should be treated. I believe that such assumptions have a great impact not only on doctors or psychologists, but primarily on patients, which may incite prejudice related to mental diseases and mentally-ill patients.

So, now I'm going to focus on a common view of a nature of somatic and psychological explanations and a relation between them. On the one hand, medical or biological explanations are seen as stricter, causal, rather purely somatic, non-individualistic, and nonnormative (Machamer, Darden, \& Craver, 2000). On the other hand, psychological or humanistic explanations are seen rather in terms of reasons (as opposed to causes), they are rather mental (in a broad sense, including social and existential contexts) and individualistic (Anscombe, 1957). These two kinds of explanations are sometimes seen as extremely separate, even by definition. As Franco de Masi put it:

I treat confrontation with other fields of knowledge as indispensable and useful but the integration is neither useful nor possible and this is because of a specific epistemological basis of psychoanalysis. (de Masi, 2018, p. 13 [translation mine])

What are those assumptions that are so difficult to debunk and why they are so influential? One of the philosophical assumptions - a division of mind from the body-comes from the Cartesian tradition. Seeing mind as exclusively human leads straight to a catastrophic belief that only adult mentally-health humans belong to the realm of rationality (e.g., Davidson, 1982). This assumption pushes both people with psychiatric disorders and animals, thus non-human minds, to the realm of irrationality. This could lead, in turn, together with a psychological mechanism of being afraid of the incomprehensible, to a stigmatization of mentally-ill people and animals.

The second assumption is that intentional mental states (i.e., mental states that are about something) take form of propositional attitudes that demands for linguistic syntax and linguistic medium (Ciecierski, 2013). It is assumed additionally that only language-like mental states, usually posited only on a so-called personal level (Dennett 1969) can be intentional. This however excludes by default a large amount of mental states on subpersonal level that are non-propositional in that sense, such as bodily representations, some perceptual representations or emotions (e.g., Davidson, 1963). But it is not necessary to assume that all representational states have a form of propositional attitudes. To take a simple example: hate is a representational mental state, as it is directed towards someone or something. But it is not (necessarily) an attitude towards a proposition or state of affairs (Crane 2003, p. 13). In case of depression (a modern term for melancholy), it seems to be 
quite plausible to ascribe depressed persons an attitude towards some utterances about the world and their situation. And it is not a whole story, while we should not forget about emotional factors that play a crucial role here and a possible understanding them as intentional, which Crane considers following Sartre view on emotions as intentional states (Crane, 2003, p. 11). Moreover, it may seem that in some mental disorders, patients confabulate unknowingly and constantly, and hence, they may produce linguistic utterances without really asserting them, which will mean that it could be difficult to ascribe them any attitude towards these utterances.

The last but not least is the assumption that explanation in mental terms cannot be integrated with an explanation in physical terms. This assumption follows from Cartesian view of mind as distinct from the body but also from a more moderate view on the status of what is mental and what is physical, such as some kind of non-reductive physicalism. Antagonists of mental explanation often assume that mental disorder is actually a human reaction to environmental and social situation, not a physical disorder (Middleton \& Moncrieff, 2019). In other words, they exclude any possibility of mental or psychological explanation in favor of a so-called medical explanation, in terms of physical or biochemical ones only. Realizing that such understood mental disorder does not exist, they then eliminate it from medicine.

As a consequence of such a strict division between the mental and the physical, many of the $20^{\text {th }}$ - and $21^{\text {st }}$-century philosophically-oriented psychiatrists still work in a conceptual framework that divide the mental from the somatic. In this sense a phenomenological approach, which considers experience as irreducible to anything physical (Jaspers, 1963; Fuchs, 2007; Fulford, 2000; Gipps \& Fulford, 2004; Kapusta 2010), can be seen as an intellectual response to a strict biologically-oriented medicine. Anti-psychiatrists crowning counterargument against psychiatry is that psychiatry promised to deliver neurological bases for mental disorders and they are still not found.

However true it is that neurological bases for certain pathologies are still unknown and maybe they would not be found, philosophically-oriented psychiatrists's attitude toward science in general is overly critical and simplistic. Psychiatry cannot be considered hard science similar to physics and having the same kinds of universal laws as physics has, because it has also chemical, biological, and eventually psychological components, and offers only ceteris paribus laws. As a result, psychiatry does not seek for an ultimate explanation of certain diseases that are independent of some individual or broader, contextual factors. Even if a neurological basis would be found, contextual factors would still play their role.

What is worrying, anti-psychiatric way of thinking became a fuel for the still growing antipsychiatric trend, according to which the concept of mental illness is a social construction (Laing, 1960; Szasz, 1960, 1997; Foucault, 1965; Cooper, 1971; Goffman, 1971). Antipsychiatric arguments are controversial in the sense that they sustain and help to develop negative attitude to evidence-based medical treatment. In spite of problems which drug therapies can induce (and objections toward them are justified), it would be disastrous for 
scientific progress if severely mentally-ill people could not have been relieved from pain and suffering by drugs to them that influence their brain chemistry to reduce stress and often save patients' lives.

\subsection{How Can Medicine and Psychology Be Brought Together?}

Some psychiatrists and philosophers of psychiatry, however, such as Kendler, Bolton, or Fullford, are aware of the problems that come out of a division between the mental and the physical and its impact on understanding why even some disordered mental states mean something (or are about something), but there is still work to be done in the field. Kendler is aware of that "psychiatry needs to move from a prescientific 'battle of paradigms' toward a more mature approach that embraces complexity along with empirically rigorous and pluralistic explanatory models" (Kendler, 2005, p. 433). Kendler's so-called integrative pluralism tries to incorporate divergent levels of analysis and seeks for local integrations across levels of analysis one at a time (p. 438). In other words, Kendler is aware of the mixed-bag of psychological and biological descriptions and explanations. The hate or contempt coming from both sides - scientific and humanistic - eventually became too heavy to remain without any changes in thinking:

The split between science and meaning was bound to lead to assault by the one side against the other for excluding it: sympathy with meaning led to outrage against scientific psychiatry, and adherence to science led to contempt for speculations about meaning. This mutual hatred - if that is not too strong a word — was a sign that the split had become intolerable; dialectical synthesis was already in the making. (Bolton, 1997, p. 255)

This leads to the question of what kind of direction could integration of science and meaning take. Bolton believes in a promising evolutionary perspective, in which Nesse's claim of evolution as a missing half of a truly biological psychiatry fits very well (Nesse, 2009). An evolutionary approach promises that scientific and humanistic view on how-so called - disordered beliefs are to be explained, can be conjoined. An individual organism (along with its parts) is understood holistically, as a part of its environment, and influenced by environmental (biological or physical) factors. It means that mental states relate to other (biological, physical) states, so they can be explained in terms of biological states. Here is also a place for a mutual influence between an organism and its environment (including other organisms and species). As a result, neither biology nor psychology can take a bare individual without environmental or contextual factors. Also, a dualism between the mental and the physical is impossible in the view. Such a perspective shows that there is really one paradigm of explanation of meaning possible, one that finds a place for psychological factors in a broad biological explanation. In other words, meaning or intentional nature of some mental states would be understood as a result of other more biological factors. What is more, human and non-human rationality are not clear-cut but they are in the same continuum. Only one form of rationality that is in biology is an instrumental rationality, that is all about having certain goals and means that organisms take to achieve them. 


\section{A Naturalistic Understanding of Mental Disorders}

In the previous section, I argued that an evolutionary perspective in life sciences is promising in that it undermines some assumptions leading to a dualism between mind and the mental, as well as helps us to broaden the realm of rationality in order to include people with mental disorders and non-human minds. An evolutionary perspective on rationality makes it possible to attribute content also to thoughts of animals and people with mental disorders. In other words, there is a reason to think of them as having intentional mental states. So, let me now present a philosophical framework that complements an evolutionary view with a draft of an account of naturalized meaning.

The view I will show is a kind of integrative naturalism, according to which new entities are posited only if a theoretical justification coming from empirical investigation can be supplied.

In integrative naturalism, intentional states can be explicated in non-intentional terms. According to a common philosophical view, meaning of a linguistic item is seen as analogical to the content of mental representation (Pitt, 2013). Intentional mental states are then mental representations that have their targets (if any), vehicle (for example, a neuronal state) and content (satisfaction or accuracy conditions). Thanks to the content, a mental representation, such as thought or belief, can be true or false, adequate or not. False or inadequate mental representations are mental misrepresentations.

One might ask why such a concept of mental representation is necessary in the naturalistic account of the mental. My argument is that one should not assume universal irrationality of biological agents. However, without mental representation and, especially, misrepresentation, all our thoughts that lead to actions that are unsuccessful would be irrational (in the sense of instrumental rationality). Suppose for example that a man stands at a bus station waiting for a bus to the university, although the bus has not arrived for a long time. What we would think of his behavior is probably that he made a mistake, for example did not check the time-table and did not know that his bus came earlier, etc. In other words, he had an inadequate belief about his bus coming, so he had a mental misrepresentation. Probably, the next time he would double-check the time-table to correct his misrepresentation about the time of his bus coming. Similarly, the same could be thought of an animal, e.g., rat searching for its food in a maze. How could its surprise (that triggers a higher level of dopamine in appropriate brain circuits) while no food is in place, in which it used to be before, could be better explained than via misrepresentation that the animal had about its food location? Without the possibility to attribute cognitive mistakes to agents, all our thoughts that lead to unsuccessful actions would be therefore irrational. It is because there would be no place for false thoughts leading to the wrong action. The possibility to think of taking wrong action means to the aims in terms of false intentional states enable us to think of rational agents as agents that make also cognitive mistakes. Only such agents are rational that are able to recognize and correct their own errors, so, in other words, recognize accuracy conditions of their mental states. 
Disordered intentional mental states are forms of misrepresentation. Let us take a dagger in Macbeth's hallucination. The dagger is Macbeth's misrepresentation that doesn't have any target (because it doesn't refer to anything real). Hallucinations seem to be clearly representational, but there are some more mental disorders, such as depression or OCD, whose representational nature is not immediately obvious. There is an ongoing debate on whether OCD can be understood representationally or just behaviorally. At least some OCDs can be representational (Bielecka \& Marcinów, 2017).

In order to understand intentional mental states and their content (accuracy conditions) naturalistically, hence in evolutionary biological terms, I will use the concept of biological function. According to Millikan's biosemantics, which I find the most compatible with evolutionary theory, an organism (or its part) has a proper representational function $\mathrm{F}$ if in the history of a type of an organism a feature $\mathrm{C}$ was selected for F. For example, a frog's visual system has a proper representational function if the visual apparatus in the frogs' history was selected for F. Tokens of representation have a derived representational function, which means that some tokens can be dysfunctional, so they are misrepresentations. So, a frog represents a fly, if certain Normal conditions, external and internal factors to the organism, are fulfilled; if not, it misrepresents. In other words, a biological function is minimally normative and it allows us to account for misrepresentation.

A representational mechanism is responsible for a representational function. Such a mechanism has two cooperating elements: producer and consumer. The former is responsible for producing only such information that can be further evaluated by a consumer and both stages of a processing of representation are necessary for a representation to appear. The idea of a consumer is taken from the idea that a sign or trace that does not mean anything unless there is a possibility of recognizing it as this sign or trace. Information is representational only if it could be recognized.

In my view, which goes beyond Millikan's (1984) model, an organism itself should recognize a representation as accurate or not. Otherwise, it would be only a representation in the eye of a beholder (Bickhard, 2009). So, to recognize a misrepresentation is to recognize the incoherence between the representations $\mathrm{A}$ and $\mathrm{B}$ and its consumer is able to register an incoherence between representations (or representation and information). To be able to correct a misrepresentation $\mathrm{A}$, an organism must be able to recognize the misrepresentation $\mathrm{A}$ and to its realization suffices an ability to recognize a degree of reliability of information $\mathrm{A}$ and $\mathrm{B}$. If then an information $\mathrm{B}$ is more reliable than $\mathrm{A}$, then a representation $\mathrm{A}$ is a misrepresentation. An ability to correct allows the organism to learn, e.g., via reinforcement learning (for more, see Bielecka \& Marcinów, 2017).

Let's take an example of a patient suffering from OCD that compulsively wash her hands after her mother's sudden death (Borsboom, Cramer, \& Kalis, 2019). One could explain such a behavior in purely behavioral terms as a response to a constant fear of having hands dirty. However, concentration on the compulsive behavior only wouldn't allow for a complete etiological explanation of this disease. According to the representational explanation in terms of proper function, a patient has a representational function that is distorted, or 
simply, a dysfunction. As each cognitive system a patient represents not only proximal, but also distal stimuli. The appropriate phenomenon to be explained are not her obsessive thoughts about dirty hands as such. Dirty hands are a symptom of an aversive distal stimulus of escape from thoughts of death and a kind of response to this stimulus, which is washing hands, seems to be helpful for this patient's mental health. It is then reasonable to think of such misrepresentations as obsessive thoughts - before they become very invasive - as serving an adaptive function of protecting the patient from fearful or difficult thoughts about her mother's death. Being so obsessive, these thoughts lead to compulsions and these organism's features that allow such compulsions to appear are merely locally adaptive. As a further consequence, they don't lead a patient to elimination of her feeling of loss and they paralyze her other thoughts and actions (some of which are definitely more constructive). According to the account of biological function sketched above, a patient's organism is not in Normal conditions necessary for a representational function to be served. An alternative way of thinking of dirty hands comes out of a dysfunction of consumer of representation, responsible for ordering and retrieving representations. A consumer subsystem overreacts in evaluating only one type of information from the external world and at the same time makes it impossible for the producer to create new representations of the type (representations of hands as clean). In other words, a producer subsystem is unable to consolidate new sensory information and send them further to the brain. What is more, a patient does not recognize her misrepresentation by herself and because of the overreacting consumer subsystem she is unable to register inconsistency between sensory information and misrepresentation of her hands being dirty. What is even more important, she cannot further register an aversive distal stimulus, that is her mother's death.

As I see psychiatry from this perspective, I don’t find Marcinów’s methodological assumption regarding the autonomy of emerging clinical psychology from medical sciences satisfactory. Not only treating psychology separately is only apparently historically neutral ( $19^{\text {th }}$-century psychiatry is replete with reductive proposals such as phrenology) but alsowhich is even more important - seeing psychological and biological descriptions and explanations as non-homogenous or mixed-bag, sometimes even conflicted, can actually enlighten how the concept of melancholy developed to eventually dissolve in the $20^{\text {th }}$ century. Showing how different paradigms or views on melancholy influenced each other would be showing a real historical process of the concept development.

To summarize, I argued for a philosophical account of psychopathologies that is compatible with biology. As such, it demands for continuity between mind and body, restricted individualism, some kind of integration between psychology and natural sciences and minimal biological norm. I tried to show that such an account can help to preserve rationality in psychopathologies. Firstly, I proposed an argument from rationality showing that misrepresentations (especially ones that can be corrected) are signs of being rational and secondly, I argued that mental disorders (as in an example of OCD) serve a locally adaptive function, if they could be considered as mental misrepresentations. This kind of philosophical framework might have better served to enlighten psychiatry in its historical development, in which both biological and psychological views influence each other. 


\section{Conclusion}

Mira Marcinów in her book discovered interesting examples of melancholic cases that show how strongly the beginning of psychiatry was influenced by dualistic philosophical assumptions. It strikes me how similar the past psychiatry is to psychiatry nowadays. I tried to tease out the major philosophical assumptions implicit in the book and their impact on thinking of mental disorders and their treatment. I searched for an approach that would be a way out from such prejudices via a common ground for scientific and humanistic explanation in psychiatry, which I find most compelling from both medical and patient's (humans and non-humans) perspective. Eventually, I sketched an account of how certain mental disorders could be considered as related to intentionality in an evolutionary approach toward meaning. I argued for an account that allows for the local integration between different (physical, biological, psychological) aspects of explanation of certain psychopathologies. At the same time, I argued for an account that could also retain limited rationality of humans as well as other animals with mental disorders. Last but not least, I showed that such an alternative philosophical account is much more fruitful in understanding psychiatry in its historical process.

\section{Acknowledgements}

The work on this paper was funded by National Science Centre 2016/ 23/ D/ HS1/ 02205 (PI: Krystyna Bielecka).

\section{References}

Ahn, W., Proctor, C. C., \& Flanagan, E. H. (2009). Mental Health Clinicians' Beliefs About the Biological, Psychological, and Environmental Bases of Mental Disorders. Cognitive Science, 33(2), 147-182. https://doi.org/10.1111/j.1551-6709.2009.01008.x

Anscombe, G. E. (1957). Intention. Oxford, UK: Basil Blackwell

Bickhard, M. H. (2009). The interactivist model. Synthese, 166(3), 547-591.

https://doi.org/10.1007/s11229-008-9375-x

Bielecka, K., \& Marcinów, M. (2017). Mental Misrepresentation in Non-human Psychopathology. Biosemiotics, 10(2), 195-210. https://doi.org/10.1007/s12304-017-9299-2

Borsboom, D., Cramer, A., \& Kalis, A. (2018). Brain disorders? Not really... Why network structures block reductionism in psychopathology research. Behavioral and Brain Sciences, 42, 1-54. https://doi.org/10.1017/S0140525X17002266

Ciecierski, T. (2013). Nastawienia sądzeniowe: Wykłady z filozofii psychologii. Warszawa, Poland: Wydawnictwo Naukowe PWN. 
Cooper, D. (1967). Psychiatry and Anti-psychiatry. London, UK: Paladin.

Crane, T. (2003). The Mechanical Mind ( $2^{\text {nd }}$ ed.). London, UK: Routledge.

Davidson, D. (1963). Actions, reasons and causes. Journal of Philosophy, 60(23), 685-700.

Davidson, D. (1982). Rational animals. Dialectica, 36(4), 317-328.

de Masi, F. (2018). Wyktady z psychoanalizy: Pojęcia i historia ich rozwoju. Warszawa, Poland: Oficyna Ingenium.

Dennett, D. (1969). Content and Consciousness. London, UK: Routledge \& Kegan Paul.

Foucault M. (1965). Madness and Civilization: A History of Insanity in the Age of Reason. (R. Howard, Trans.). New York, NY: Vintage.

Foucault, M. (1970). The order of things: An archaeology of the human sciences. London, UK: Tavistock Publications.

Fuchs, T. (2007). Psychotherapy of the Lived Space: A Phenomenological and Ecological Concept. American Journal of Psychotherapy, 61(4), 423-439. https://doi.org/10.1176/appi.psychotherapy.2007.61.4.423

Fulford, K. W. M. (2000). Teleology without Tears: Naturalism, Neo-Naturalism, and Evaluationism in the Analysis of Function Statements in Biology (and a Bet on the Twenty-first Century). Philosophy, Psychiatry, \& Psychology, 7(1), 77-94.

Gipps, R. G. T., \& Fulford, K. W. M. (Bill). (2004). Understanding the clinical concept of delusion: from an estranged to an engaged epistemology. International Review of Psychiatry, 16(3), 225235. https://doi.org/10.1080/09540260400003966

Goffman, E. (1971). Insanity of Place. In: Relations in Public, Microstudies of the Public Order. London, UK: Harper, p. 335-390.

Jaspers K. (1963).General Psychopathology. (J. Hoenig, M. W. Hamilton, Trans.). Chicago, IL: University of Chicago Press.

Kendler, K. S. (2005). Toward a Philosophical Structure for Psychiatry. American Journal of Psychiatry, 162(3), 433-440. https://doi.org/10.1176/appi.ajp.162.3.433

Laing, R. D. (1960). The Divided Self: An Existential Study in Sanity and Madness. Harmondsworth, UK: Penguin.

Marcinów, M. (2017). Historia polskiego szaleństwa. Słońce wśród czarnego nieba: studium melancholii (Vol. 1). Gdańsk, Poland: Fundacja Terytoria Książki.

Micale, M. S., \& Porter, R. (Eds.). (1994). Discovering the history of psychiatry. New York, NY: Oxford University Press.

Middleton, H., \& Moncrieff, J. (2019). Critical psychiatry: A brief overview. BJPsych Advances, 25(1), 47-54. https://doi.org/10.1192/bja.2018.38

Millikan, R. G. (1984). Language, thought, and other biological categories: New foundations for realism. Cambridge, MA: The MIT Press.

Nesse, R. M. (2009). Evolution at 150: Time for truly biological psychiatry. The British Journal Psychiatry, 195(6), 471-472. https://doi.org/10.1192/bjp.bp.109.072074 
Pitt, D. (2013). Mental Representation. In E. N. Zalta (Ed.), The Stanford Encyclopedia of Philosophy. Retrieved from http://plato.stanford.edu/archives/fall2013/entries/mental-representation/

Szasz, T. (1960). The Myth of Mental Illness. American Psychologist, 15, 113-118.

Szasz, T. (1997). The Manufacture of Madness: A Comparative Study of the Inquisition and the Mental Health Movement. Syracuse, NY: Syracuse University Press.

Walicki, A. (2000). L. Kołakowski i warszawska szkoła historyków idei. In R. Sitek (Ed.), Warszawska szkoła historii idei. Między historia a teraźniejszością (pp. 229-249). Warszawa, Poland: Scholar.

The editorial and publishing process of this publication has been financed by the Ministry of Science and Higher Education from the funds for the dissemination of research (DUN) within the framework of publishing activity, contract no. 711/P-DUN/2019, period of implementation: the years 2019-2020. 